\title{
Updated MISR over-water research aerosol retrieval algorithm - Part 2: A multi-angle aerosol retrieval algorithm for shallow, turbid, oligotrophic, and eutrophic waters
}

\author{
James A. Limbacher ${ }^{1,2,3}$ and Ralph A. Kahn ${ }^{1}$ \\ ${ }^{1}$ Earth Science Division, NASA Goddard Space Flight Center, Greenbelt, MD 20771, USA \\ ${ }^{2}$ Science Systems and Applications Inc., Lanham, MD 20706, USA \\ ${ }^{3}$ Department of Meteorology and Atmospheric Science, the Pennsylvania State University, State College, PA 16802, USA
}

Correspondence: James A. Limbacher (james.limbacher@nasa.gov)

Received: 25 June 2018 - Discussion started: 7 September 2018

Revised: 3 December 2018 - Accepted: 6 December 2018 - Published: 30 January 2019

\begin{abstract}
Coastal waters serve as transport pathways to the ocean for all agricultural and other runoff from terrestrial sources, and many are the sites for upwelling of nutrientrich, deep water; they are also some of the most biologically productive on Earth. Estimating the impact coastal waters have on the global carbon budget requires relating satellite-based remote-sensing retrievals of biological productivity (e.g., chlorophyll $a$ concentration) to in situ measurements taken in near-surface waters. The Multi-angle Imaging SpectroRadiometer (MISR) can uniquely constrain the "atmospheric correction" needed to derive ocean color from remote-sensing imagers. Here, we retrieve aerosol amount and type from MISR over all types of water. The primary limitation is an upper bound on aerosol optical depth (AOD), as the algorithm must be able to distinguish the surface. This updated MISR research aerosol retrieval algorithm (RA) also assumes that light reflection by the underlying ocean surface is Lambertian. The RA computes the ocean surface reflectance $\left(R_{\mathrm{rs}}\right)$ analytically for a given AOD, aerosol optical model, and wind speed.

We provide retrieval examples over shallow, turbid, and eutrophic waters and introduce a productivity and turbidity index (PTI), calculated from retrieved spectral $R_{\mathrm{rs}}$, that distinguished water types (similar to the the normalized difference vegetation index, NDVI, over land). We also validate the new algorithm by comparing spectral AOD and Ångström exponent (ANG) results with 2419 collocated AErosol RObotic NETwork (AERONET) observations. For AERONET $558 \mathrm{~nm}$ interpolated AOD $<1.0$, the root-meansquare error (RMSE) is 0.04 and linear correlation coefficient
\end{abstract}

is 0.95 . For the 502 cloud-free MISR and AERONET collocations with an AERONET AOD $>0.20$, the ANG RMSE is 0.25 and $r$ is 0.89 . Although MISR RA AOD retrieval quality does not appear to be substantially impacted by the presence of turbid water, the MISR-RA-retrieved Ångström exponent seems to suffer from increased uncertainty under such conditions.

MISR supplements current ocean color sources in regions where sunglint precludes retrievals from single-view-angle instruments. MISR atmospheric correction should also be more robust than that derived from single-view instruments such as the Moderate Resolution Imaging Spectroradiometer (MODIS). This is especially true in regions of shallow, turbid, and eutrophic waters, locations where biological productivity can be high, and single-view-angle retrieval algorithms struggle to separate atmospheric from oceanic features.

\section{Introduction}

Although coastal and generally turbid waters represent some of the most biologically productive waters in the world, constraining their impacts on the global carbon budget remains challenging (Bauer et al., 2013; Behrenfeld et al., 2005). One reason is the need to account for the contribution the atmosphere makes to the observed, top-of-atmosphere (TOA) signal obtained from frequent, large-scale, remote-sensing observations. Aerosol loading tends to be considerably higher over coastal waters than over the remote ocean, and the in- 
ability of many aerosol retrieval algorithms to separate surface from atmospheric features in complex coastal water zones precludes accurate surface retrievals.

The NASA Earth Observing System's (EOS) Multiangle Imaging SpectroRadiometer (MISR) instrument was launched aboard the Terra satellite on 18 December 1999. The satellite moves north to south on the day side of the planet, in a $\sim 700 \mathrm{~km}$ Sun-synchronous orbit with a local 10:30 equator-crossing time (dayside) and a $\sim 98^{\circ}$ orbital inclination. Originally intended as a 6-year mission, MISR continues to operate nominally more than 18 years later. The instrument samples upwelling radiance over a $\sim 400 \mathrm{~km}$ wide swath in four spectral bands centered at $446 \mathrm{~nm}$ (blue), $558 \mathrm{~nm}$ (green), $672 \mathrm{~nm}$ (red), and $866 \mathrm{~nm}$ (near-infrared, or NIR) (Diner et al., 1998). These measurements are taken for each of the nine MISR cameras, viewing in both the forward and aft directions along the satellite's orbit $( \pm 70.5$, $60.0,45.6,26.1$, and $0.0^{\circ}$ or nadir), resulting in optical path lengths that vary from one to three. (Throughout this paper, the nadir camera is designated "An"; the forward and aft-viewing $26.1^{\circ}$ cameras "Af" and "Aa", respectively; and those viewing at $45.6,60.0$, and $70.5^{\circ}$ as "B", "C", and "D", respectively.) MISR radiance data are generally recorded at $1.1 \mathrm{~km}$ resolution, but data for all nine cameras from the red band are retained at $275 \mathrm{~m}$, as are data from all four spectral bands at nadir. Additionally, MISR samples selected regions at roughly $275 \mathrm{~m}$ in all 36 channels (the A, B, C, and D cameras have different focal lengths to provide uniform spatial resolution) consistently for $\sim 15$ years (i.e., consistent, longterm, high-resolution data), resulting in a high-resolution, high-information-content dataset suitable for heterogeneous coastal water retrievals.

In recent years, many in situ measurements of near-surface biological constituents, including chlorophyll $a$ concentration (Chl), have been taken jointly with measurements of remote-sensing reflectance $\left(R_{\mathrm{rs}} ; \mathrm{sr}^{-1}\right) . R_{\mathrm{rs}}$ represents the normalized (see Morel et al., 2002) upward-directed radiance $\left(L_{w} ; \mathrm{W} \mathrm{m}^{-2} \mu \mathrm{m}^{-1} \mathrm{sr}^{-1}\right)$ just above the ocean surface, divided by the bottom-of-atmosphere (BOA), downwarddirected spectral irradiance $\left(E_{\mathrm{d}} ; \mathrm{W} \mathrm{m}^{-2} \mu \mathrm{m}^{-1}\right)$. $R_{\mathrm{rs}}$ is widely used in the ocean color community because it can be directly related to near-surface biological proxies (measured in situ; such as chlorophyll $a$ ) and can be estimated in the field from surface remote-sensing observations, as described in Mobley (1999). As much remote-sensing-based ocean color research has focused on relating measurements of biological proxies to $R_{\mathrm{rs}}$ empirically (Werdell and Bailey, 2002, 2005), two different strategies have emerged that make use of $R_{\mathrm{rs}}$. The purely empirical approach to retrieving ocean color properties relates ratios of normalized $R_{\mathrm{rs}}$ to parameters such as Chl statistically (e.g., see O'Reilly et al., 1998; Morel and Gentili, 2009; Hu et al., 2012). A semi-analytical method involves using a combination of radiative transfer theory (Morel et al., 2002) and empirical observations (e.g., Morel and Prieur, 1977; Lee et al., 2015) to retrieve Chl and other parameters (e.g., Maritorena et al., 2002; Werdell et al., 2013). Fundamentally, both techniques rely on high-quality retrievals of $R_{\mathrm{rs}}$, which is dependent on the quality and spectral dependence of the "atmospheric correction" (Kahn et al., 2016), as well as the calibration of the instrument.

Mobley et al. (2016) summarize the atmospheric correction procedure implemented in the ocean color algorithm used for the Moderate Resolution Imaging Spectroradiometer (MODIS) and the Sea-Viewing Wide Field-of-View Sensor (SeaWiFS) at the NASA Goddard Space Flight Center (GSFC). For dark (case I) water retrievals, where the remotesensing reflectance is negligible for the near-infrared wavelengths, the retrieval process follows directly from the one proposed by Gordon and Wang (1994), with updates made to the aerosol optical models (Ahmad et al., 2010) and spectral bands used. For case II waters, where $R_{\mathrm{rs}}$ in two NIR bands used is not necessarily negligible (or even identical), the algorithm follows an iterative scheme described in Bailey et al. (2010), initialized with a guess of $R_{\mathrm{rs}}$ (NIR) equal to 0 .

With nine cameras taking measurements at four wavelengths, MISR has the angular information content needed to constrain aerosol properties, even over bright turbid water, but lacks the specific spectral bands optimal for ocean color applications, though it can fill in glint-contaminated regions of single-view instruments such as MODIS (Limbacher and Kahn, 2017). As such, this paper focuses on MISR's ability to retrieve the atmospheric component, aerosol amount, and type over shallow, turbid, and eutrophic waters, as well as over oligotrophic waters. The paper is organized as follows: Sect. 2 outlines the datasets and methodologies used, example retrievals are shown in Sect. 3, validation is presented in Sect. 4, and conclusions are given in Sect. 5.

\section{Upgraded MISR research aerosol retrieval algorithm (RA) and comparison datasets}

\subsection{The over-water MISR RA methodology}

The MISR standard aerosol product (SA; Diner et al., 2008; Martonchik et al., 2009) provides publicly accessible aerosol amount and type information globally at $4.4 \mathrm{~km}$ spatial resolution (Kahn et al., 2010; Kahn and Gaitley, 2015; Garay et al., 2017). In contrast, the RA can only process MISR data for selected locations and times, on a case-by-case basis, but offers spatial resolution down to $1.1 \mathrm{~km}$ or $275 \mathrm{~m}$ pixel size, advancements in radiometric calibration critical for aerosoltype retrieval, an improved surface representation, and the option of a greatly expanded aerosol optical model climatology (Limbacher and Kahn, 2014, 2015, 2017). Briefly, the RA finds the set of aerosol optical models, associated aerosol amounts, and $R_{\mathrm{rs}}$ values that minimize the difference between the observed TOA reflectances and simulated values that are stored in a look-up table (LUT). These dimensionless TOA reflectances are computed from the observed radiances 
according to the following:

$\rho_{\lambda, c}^{\mathrm{TOA}}=L_{\lambda, c} \cdot \frac{\pi \cdot D^{2}}{E_{\lambda}^{\mathrm{TOA}}}$,

where $L_{\lambda, c}$ represents the TOA observed radiance $\left(\mathrm{W} \mathrm{m}^{-2} \mu \mathrm{m}^{-1} \mathrm{sr}^{-1}\right.$ ) in band $\lambda$ and camera $c, D$ is the Earth-Sun distance at the time of observation in astronomical units (AU), and $E_{\lambda}^{\mathrm{TOA}}$ is the exoatmospheric solar irradiance at $1 \mathrm{AU}\left(\mathrm{W} \mathrm{m}^{-2} \mu \mathrm{m}^{-1}\right)$. We then correct these TOA reflectances for the following (described in Limbacher and Kahn, 2015, 2017): gas absorption, out-of-band light, stray light from instrumental artifacts, flat-fielding (pixelto-pixel inconsistency), and temporal calibration trends. Even with the near-nadir-camera ghosting corrections implemented in Limbacher and Kahn (2015), we found it necessary to include an additional veiling-light correction (similar to Witek et al., 2017) to bring the aerosol optical depths (AODs) into better agreement with the AErosol RObotic NETwork (AERONET); ghosting corrections for the off-nadir cameras are currently under study by the JPL MISR team.

The fundamental physical assumption of this algorithm is that the camera-averaged remote-sensing reflectances $\left(R_{\mathrm{rs}}\right.$; including any reflection off of the underlying sea floor) can be adequately approximated as Lambertian. (This is supported by the $f / Q$ corrections found in Morel et al., 2002.) The addition of an $f / Q$ correction $(f / Q$ represents a nonLambertian bidirectional surface modification; such as from Morel et al., 2002) would increase the robustness of this algorithm over deep-water regions, at the expense of computational time and simplicity. We chose to keep the model simple for this paper. The objective of our algorithm is to selfconsistently retrieve AOD and remote-sensing reflectance at $1.1 \mathrm{~km}$ resolution, for any set of aerosol optical models used, such as those found in Limbacher and Kahn (2014). We run the RA for all optical models found in our LUT, aggregating the resulting AOD and aerosol properties corresponding to the best-fitting AOD for each candidate aerosol mixture according to an exponential weighting of our cost function $(M)$,

$M=\sum_{\lambda} \sum_{c} \frac{w_{\lambda, c} \cdot\left[\rho_{\lambda, c}^{\mathrm{TOA}}-\left(\rho_{\lambda, c}^{\mathrm{Model}}+E_{\lambda}^{\mathrm{BOA}} \cdot R_{\mathrm{rs}, \lambda} \cdot T_{\lambda, c}^{\mathrm{up}}\right)\right]^{2}}{\mathrm{Unc}_{\lambda, c}^{2} \cdot\left[\sum_{\lambda} \sum_{c} w_{\lambda, c}\right]}$,

Mix_Weight $=\exp \left(\frac{M_{\text {Min }}-M}{M_{\text {Min }}+0.01}\right)$.

The channel-specific weights are $w_{\lambda, c}$ (detailed in Sect. 2.1.3 below), the assumed uncertainty for the model-measurement system is $\mathrm{Unc}_{\lambda, c}$ (detailed in Sect. 2.1.3), and $\rho_{\lambda, c}^{\text {Model }}$ represents the effects of atmospheric gas and aerosol scattering, plus the combined TOA effects of Fresnel reflection (modeled as an isotropic Cox-Munk surface) and whitecaps. The term $E_{\lambda}^{\mathrm{BOA}} \cdot R_{\mathrm{rs}, \lambda} \cdot T_{\lambda, c}^{\mathrm{up}}$ represents the TOA contribution of light reflected by a Lambertian surface with spectral albedo $R_{\mathrm{rs}, \lambda}, E_{\lambda}^{\mathrm{BOA}}$ is the bottom-of-atmosphere downward-directed irradiant reflectance (a normalized irradiance, analogous to the TOA reflectance), and $T_{\lambda, c}^{\mathrm{up}}$ is the azimuthally averaged upward transmittance from the surface to the MISR camera of interest. Mix_Weight represents the individual weight given to each aerosol mixture for aggregating aerosol properties into one effective mixture, and $M_{\text {Min }}$ represents the minimum cost function among all aerosol mixtures. The choice of inverse exponential weighting was made to avoid the use of specific mixture acceptance thresholds that would arbitrarily exclude some mixtures entirely.

\subsubsection{Research algorithm detailed description}

To retrieve the remote-sensing reflectance, we prescribe the wind-driven effects of a roughened ocean surface (glint and whitecaps), using Cross-Calibrated Multi-Platform (CCMP; $0.25^{\circ}, 6$ hourly) $10 \mathrm{~m}$ wind speed version 2 data (Atlas et al., 2011; Wentz et al., 2015). The Rayleigh scattering contribution to TOA reflectance is prescribed with a 1013.25 mbar surface pressure. This allows us to remove one dimension from our look-up table and has minimal impact over ocean, including coastal regions (though it might have an impact over elevated inland lakes). Once the LUT has been interpolated to the appropriate solar and viewing geometry and wind speed, we then iterate through our grid of AOD, calculating the $R_{\mathrm{rs}, \lambda}$ needed to minimize $M$. This is done by taking the derivative of Eq. (2a) with respect to $R_{\mathrm{rs}, \lambda}$, setting it equal to zero and solving for $R_{\mathrm{rs}, \lambda}$.

$R_{\mathrm{rs}, \lambda}=\frac{\sum_{c}\left[\frac{w_{\lambda, c}}{\mathrm{Unc}_{\lambda, c}^{2}} \cdot T_{\lambda, c}^{\mathrm{up}} \cdot\left(\rho_{\lambda, c}^{\mathrm{TOA}}-\rho_{\lambda, c}^{\mathrm{Model}}\right)\right]}{E_{\lambda}^{\mathrm{BOA}} \cdot \sum_{c}\left[\frac{w_{\lambda, c}}{\mathrm{Unc}_{\lambda, c}^{2}} \cdot\left(T_{\lambda, c}^{\mathrm{up}}\right)^{2}\right]}$

To prevent the algorithm from retrieving an unphysically dark surface, we establish the following $R_{\mathrm{rs}}$ minima for the blue, green, red, and NIR: [0.005, 0.003, 0.0005, 0.00008]. As there can be only one set of $R_{\mathrm{rs}, \lambda}$ that minimizes $M$ for any given AOD and aerosol mixture, $M$ becomes inherently one-dimensional (for a given aerosol mixture). We then calculate $M$ for every AOD on the AOD LUT grid until $M$ begins to increase, which is then used to calculate the first $\left(M^{\prime}\right)$ and second $\left(M^{\prime \prime}\right)$ derivatives of $M$ with respect to AOD at the minimum value of $M$ for each mixture. The AOD reported by each aerosol mixture is obtained from using Newton's method, defined as

$\tau_{\text {new }}=\tau_{\text {old }}-\frac{M^{\prime}}{M^{\prime \prime}}$.

$\tau_{\text {new }}$ is the mixture-reported AOD and $\tau_{\text {old }}$ is the AOD corresponding to the minimum value of $M$. Once $M$ is minimized for each aerosol mixture, we then aggregate acceptable aerosol mixture results by weighting AOD, aerosol proper- 
ties, and surface properties according to Eq. (2b), so betterfitting mixture-AOD-surface combinations are weighted more heavily.

\subsubsection{RA glint screening}

Building on the glint screening improvements made in Limbacher and Kahn (2017), we use a two-tier approach to account for sunglint. The first tier is a simple glitter angle test:

glitter $_{c}=\min \left\{\max \left[\frac{\left(G_{c}-10.0\right)}{20.0-10.0}, 0.0\right], 1.0\right\}$,

where $G_{c}$ represents the glitter angle relative to the view angle for a particular camera $c$. This equation yields a value of 0 when the glitter angle is within $10^{\circ}$ of the view angle, a value of 1 when the glitter angle exceeds $20^{\circ}$ of the view angle, and values spread linearly between 0 and 1 for intermediate glitter angles. Once computed, this weight is then multiplied into $w_{\lambda, c}$. As the algorithm now uses information from all cameras with glitter angles as low as $10^{\circ}$, we must include the effects of sunglint in our estimate of uncertainty. To speed up computation, the estimate of sunglint uncertainty for a given band and camera is computed for an aerosol-free atmosphere as the following:

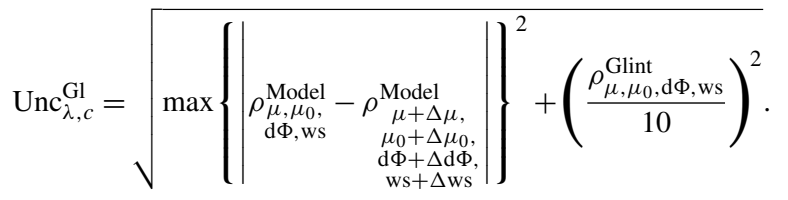

Here $\rho_{\mu, \mu_{0}, \mathrm{~d} \Phi, \mathrm{ws}}^{\mathrm{Mod}}$ represents the modeled reflectance for any given band and camera, interpolated to the observed solar and viewing geometry and wind speed for a particular location in the MISR swath. $\mu$ represents the cosine of the viewingzenith angle, $\mu_{0}$ represents the cosine of the solar-zenith angle, $d \Phi$ represents the relative-azimuth angle between the solar and viewing vectors, and ws represents the CCMP in-

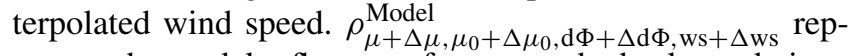
resents the model reflectance for a perturbed solar and viewing geometry and perturbed wind speed. The perturbation is $3 \mathrm{~m} \mathrm{~s}^{-1}$ for wind speed, 0.01 for $\mu_{0}$ and $\mu$, and $2^{\circ}$ for $\mathrm{d} \Phi$; this term represents an attempt to account for uncertainty in glint modeling due to wind-speed error, anisotropy, etc. $\rho_{\mu, \mu_{0}, \mathrm{~d} \Phi \text {,ws }}^{\mathrm{Glint}}$ represents the difference between the modeled TOA reflectance over a Fresnel reflector with whitecaps (dependent on ws) and the modeled TOA reflectance over a black surface. This last term in Eq. (6) is just $10 \%$ of the modeled surface-attenuated reflectance in the band and camera (squared) and is our guess at a lower bound on the reflectance uncertainty associated with sunglint.

\subsubsection{RA input uncertainties}

Previous versions of the MISR RA (as well as the SA) have attempted to characterize uncertainty only in terms of TOA observed reflectance, rather than attempting to account for uncertainty due to stray light or forward-modeling errors (such as glint). Here, we employ a heuristic approach by attempting to account for the relative magnitude of some of the largest uncertainties (the actual coefficients used for the uncertainties are educated guesses), though we neglect the fact that these uncertainties are at least partly correlated.

$$
\begin{aligned}
\mathrm{Unc}_{\lambda, c} & =\sqrt{\left(\mathrm{Unc}_{\lambda, c}^{\mathrm{TOA}}\right)^{2}+\left(\mathrm{Unc}_{\lambda, c}^{\mathrm{Gl}}\right)^{2}+\left(\mathrm{Unc}_{\lambda, c}^{\mathrm{SL}}\right)^{2}} \\
\mathrm{Unc}_{\lambda, c}^{\mathrm{TOA}} & =\sqrt{\left(0.04 \cdot \rho_{\lambda, c}^{\mathrm{TOA}}\right)^{2}+(0.002)^{2}} \\
\mathrm{Unc}_{\lambda, c}^{\mathrm{SL}} & =\sqrt{\left(f_{c} \cdot 0.01 \cdot\left[\rho_{\lambda, c}^{\mathrm{TOA}}-\rho_{\lambda, c}^{\mathrm{BG}}\right]\right)^{2}}
\end{aligned}
$$

$\mathrm{Unc}_{\lambda, c}^{\mathrm{TOA}}$ represents the uncertainty in TOA reflectance measurement, estimated here as a spectrally invariant $4 \%$ relative and 0.002 absolute. $\mathrm{Unc}_{\lambda, c}^{\mathrm{Gl}}$ represents our estimate of glint uncertainty, described in Sect. 2.1.2. As $\rho_{\lambda, c}^{\mathrm{BG}}$ represents the swath-averaged value of $\rho_{\lambda, c}^{\mathrm{TOA}}$, Unc $\mathrm{Un}_{\lambda, c}^{\mathrm{SL}}$ represents the uncertainty in our stray-light correction, given here as uniform "veiling-light" with the uncertainty set to $1 \%$ magnitude for the nadir camera. Work by Witek et al. (2017) indicates that the veiling-light error for MISR seems to increase with view angle, so we choose $f_{c}$ to be $[6,2.5,1.5,1,1,1,1.5,2.5$, 6] going from the $70^{\circ}$ forward through nadir to the $70^{\circ}$ aftviewing cameras with the additional veiling-light term set to 0.01 at nadir. As the additional veiling-light correction we apply here is identical to our stray-light uncertainty, we are indicating that there is a high degree of uncertainty associated with this correction (and our stray-light correction in general). Our channel-specific weights, $w_{\lambda, c}$ are initially set to unity, but are then multiplied by the result of Eq. (5) above.

\subsection{The AErosol RObotic NETwork (AERONET)}

AERONET sun photometers (Holben et al., 1998) provide direct measurements of spectral AOD with nominal uncertainty of \pm 0.01 (Eck et al., 1999; Sinyuk et al., 2012), verified by periodic reference calibration. The Ångström exponent (ANG), which represents the slope of a line fitted to the negative $\log$ of AOD vs. the log of wavelength, is also accurately reported as long as the spectral AOD is sufficiently large (Wagner and Silva, 2008). AERONET almucantar inversions (Dubovik and King, 2000) provide constraints on coarse-mode sphericity (Dubovik et al., 2006) and columneffective aerosol single-scattering albedo (SSA), provided the aerosol loading is high (AOD at $440 \mathrm{~nm}>0.4$ ), the Sun is low in the sky, the aerosol is spatially uniform (Holben et al., 2006), and the surrounding surface is not highly reflective (Sinyuk et al., 2007). Interpretation of the almucantar inversions is complicated when multiple aerosol modes reside in the column (Schuster et al., 2016).

For comparison with the MISR RA (Sect. 3 below), we first interpolate AERONET AOD to the MISR band centers, 
Shallow water retrieval: Florida Strait 12/22/2012, Terra Orbit 69220
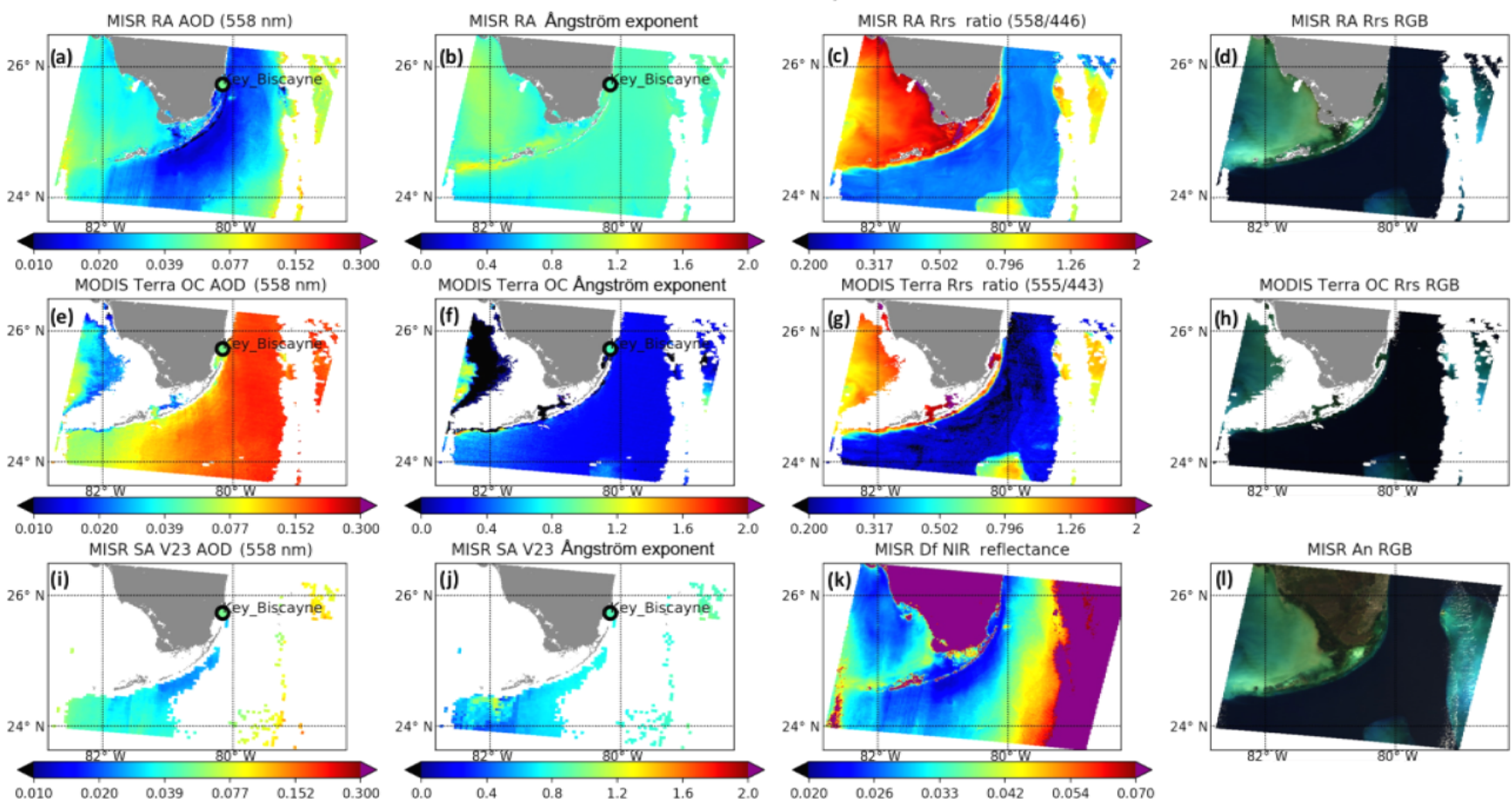

Figure 1. Example of MISR RA aerosol retrieval over shallow water. MISR imagery acquired on 22 December 2012, 16:07 Z: Terra Orbit 69220, blocks 70-71, over southern Florida and the Florida Strait. MISR RA $558 \mathrm{~nm}$ (green AOD), MODIS-Terra ocean color (OC) AOD ( $558 \mathrm{~nm}$, extrapolated using MODIS ANG), and the MISR version 23 SA AOD $(558 \mathrm{~nm})$ are presented in the first column (panels a, e, i, respectively). Plots of MISR RA ANG, MODIS-Terra OC ANG, and MISR version 23 SA ANG are provided in the second column (panels $\mathbf{b}$, f, j). MISR RA $R_{\mathrm{rs}}$ ratios $(558 \mathrm{~nm} / 446 \mathrm{~nm})$, MODIS OC $R_{\mathrm{rs}}$ ratios $(555 \mathrm{~nm} / 443 \mathrm{~nm})$, and the MISR $70.5^{\circ}$ forward-viewing near-infrared (NIR) reflectance are provided in the third column (panels $\mathbf{c}, \mathbf{g}, \mathbf{k}$, respectively). Brightness-enhanced true-color images of MISR RA $R_{\mathrm{rs}}$, MODIS-Terra OC $R_{\mathrm{rs}}$, and a MISR nadir context image (Rayleigh corrected) are presented in the fourth column (panels d, h, l, respectively). Where available, AERONET data are embedded in the plots as shaded circles matched to the scale of the relevant color bar.

using a second-order polynomial in log space: $446 \mathrm{~nm}$ (blue), $558 \mathrm{~nm}$ (green), $672 \mathrm{~nm}$ (red), and $866 \mathrm{~nm}$ (NIR). ANG is then computed as a log-log fit of interpolated AOD to wavelength (using all four wavelengths). To limit AOD spatial and temporal variability from impacting comparisons with MISR, we limit potential coincidences to $\pm 30 \mathrm{~min}$ from the MISR overpass time, saving mean spectral AOD, computing ANG from these values, and retaining the AOD deviation (max-min over time period) for all four MISR spectral bands.

\subsection{The MODIS-Terra ocean color (OC) product}

Because a main contribution of this paper is the validation of the AOD and Angström exponent from the MISR RA over complex water scenes with the MISR RA, we also compare results from the MISR RA to those from the MODIS-Terra ocean color product for a few selected scenes (OB.DAAC, $2018)$. To do this, we first re-grid the MODIS-Terra data $\left(R_{\mathrm{rs}}\right.$, AOD, ANG, and level-2 mask data; https://oceancolor.gsfc. nasa.gov/atbd/ocl2flags/, last access: 23 January 2019) to the MISR $1.1 \mathrm{~km} \mathrm{L1B2}$ projection via a nearest-neighbor ap- proach (OBPG, 2019). We then mask all data that are flagged in the MODIS level-2 product (there tend to be far fewer retrievals meeting level- 3 criteria) or fall outside of the MISR nadir-camera swath. $\mathrm{AOD}_{869}$ (NIR) is converted to $\mathrm{AOD}_{558}$ using the Ångström exponent provided in the MODIS product. Details of the algorithms used to generate MODIS OC $R_{\mathrm{rS}}$ (AOD and ANG are retrieved as part of this process) are briefly summarized in Sect. 1 above and are described in detail at https://oceancolor.gsfc.nasa.gov/atbd/rrs (last access: 16 January 2019).

\subsection{The MISR V23 standard aerosol product}

In addition to comparing the MISR RA to the MODIS OC product, we also compare the RA to the recently released MISR version 23 standard aerosol product (SA). Recent upgrades to the SA have resulted in improved spatial resolution (from 17.6 to $4.4 \mathrm{~km}$; Garay et al., 2017), better AOD statistics over ocean due to a stray-light correction (Witek et al., 2017), and the inclusion of pixel-level AOD retrieval uncertainty (over dark water only; Witek et al., 2018). Because the V23 SA reports AOD at $550 \mathrm{~nm}$, we first calculate the 


\section{Turbid water retrieval: Bay of Bengal, 1/29/2015, Terra Orbit 80397}
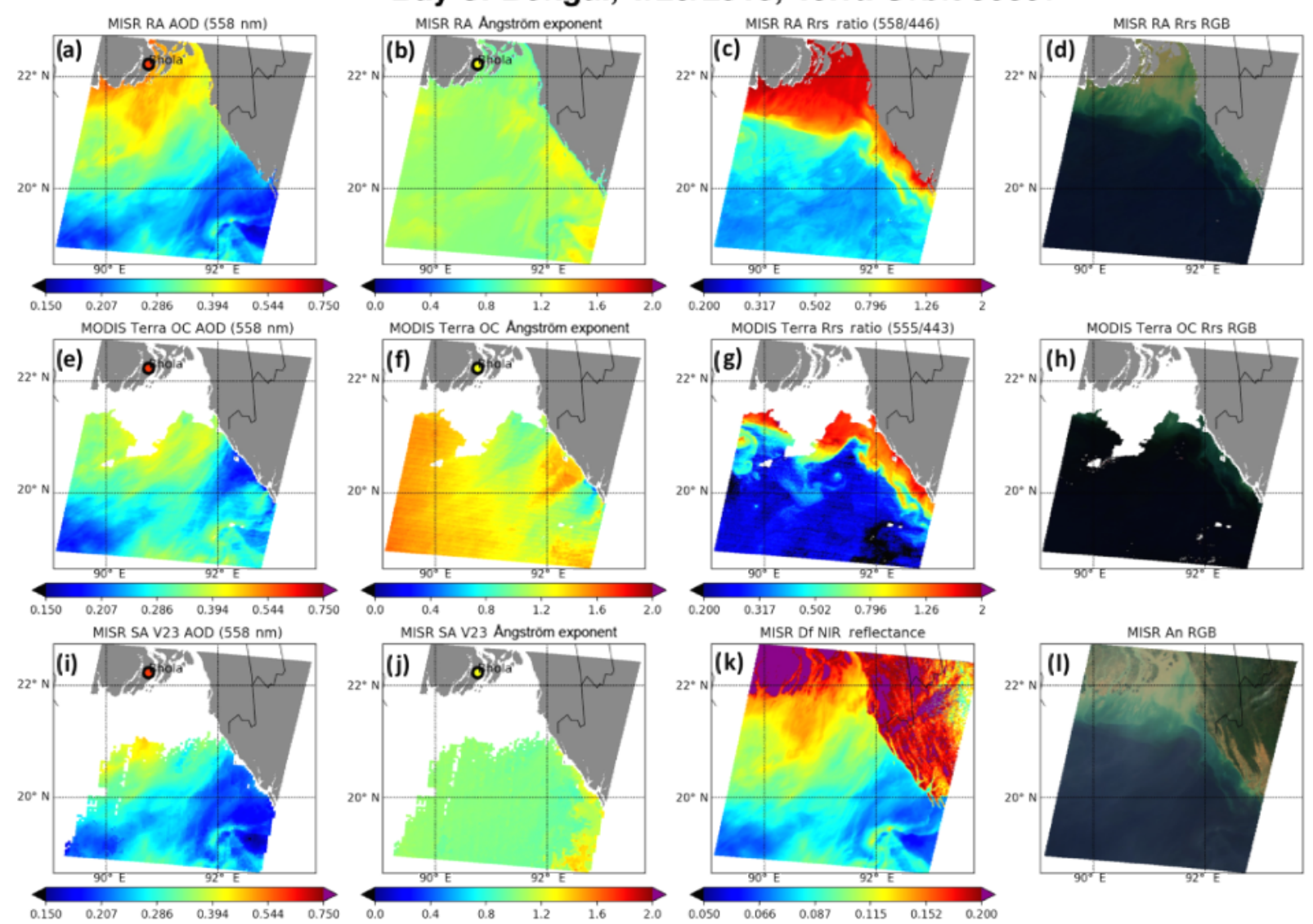

Figure 2. Same as Fig. 1, except for turbid water found in the northern Bay of Bengal. MISR imagery acquired on 29 January 2015 , 04:36Z: Terra Orbit 80397, blocks 73-75.

SA AOD for all four spectral bands using the scaling coefficients provided in the V23 product, and then calculate the Ångström exponent using all four MISR wavelengths (as described in Sect. 2.2 above). No additional cloud screening is required for the MISR SA (provided one does not use the "raw" data product, which provides AOD with minimal cloud screening).

\section{Example MISR aerosol surface retrievals over ocean}

Although much information can be gleaned from the statistical validation of MISR-retrieved spectral AOD against AERONET, scene analysis provides some useful context. In Fig. 1 we present MISR RA, MODIS-Terra OC, and MISR SA results for the Florida Strait region on 22 December 2012, including retrievals over bright (and very shallow) water. Figure 1a demonstrates the capability of the MISR RA to retrieve AOD even over the very shallow waters off the western coast of Florida. (The MISR RA $R_{\mathrm{rs}} 558 \mathrm{~nm} / 446 \mathrm{~nm}$ ratio (panel c) highlights the difference in water spectral reflectance off the Florida west coast vs. elsewhere in the region.) Compared to the MISR RA, the MISR V23 SA, and
AERONET, MODIS OC AOD (panel e) appears to be biased very high ( $>100 \%$ compared to MISR) in the eastern half of the scene, likely due to inaccurate forward modeling of sunglint or whitecaps. Also, the MODIS OC ANG values (panel f) appear to be skewed low compared to MISR and AERONET. MISR V23 SA AOD and ANG agree well with the RA in the few portions of the scene where the SA reports aerosol information, but the V23 SA masks aerosol retrievals in locations with shallow or turbid water, resulting in few retrievals over the region. Panels (c) and (g) show how the differences in retrieved aerosol properties (between the RA and MODIS) can propagate into the retrieval of $R_{\mathrm{rs}}$ and how the MISR RA atmospheric characterization allows increased coverage over near-coastal water. The retrieved $R_{\mathrm{rs}}$ for the blue band (not shown) approaches 0.3 for the region just north of Key West, which gives an indication of the versatility of the RA algorithm to retrieve over shallow water when the ocean surface is quite bright.

Figure 2 shows results for the northern Bay of Bengal on 29 January 2015, including results over notoriously turbid water. The RA indicates that the entire region is dominated by small-medium (ANG $\sim 1.0-1.2$ ) spherical non- 
Eutrophic water retrieval: Caspian Sea, 9/19/2015, Terra Orbit 83792
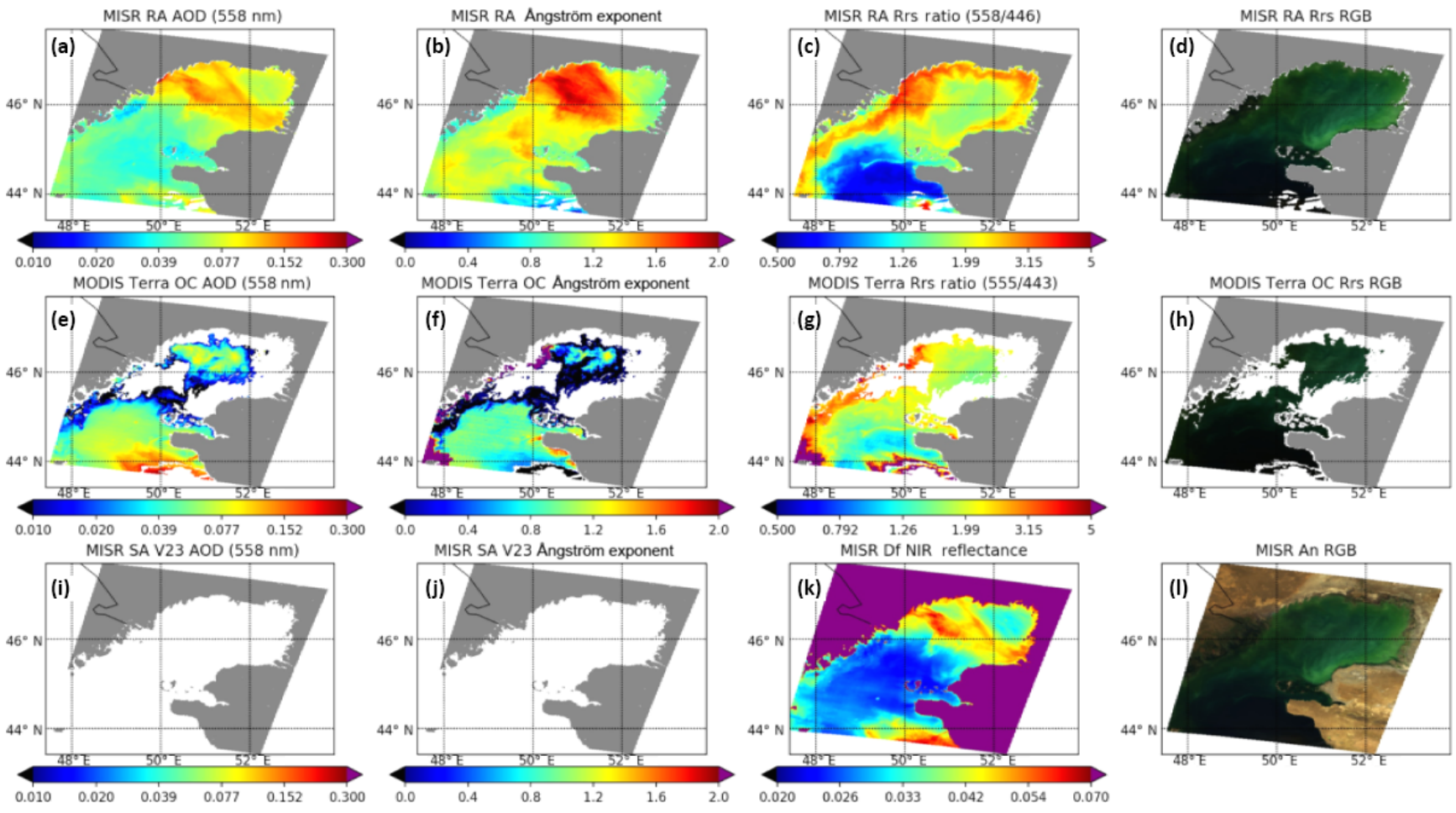

Figure 3. Same as Fig. 1, except for eutrophic waters found in the northern Caspian Sea. MISR imagery acquired on 19 September 2015 , 07:42 Z: Terra Orbit 83792, blocks 53-55. Note that there are no MISR SA V23 over-water retrievals for this region.

absorbing aerosol particles (shape and light-absorption retrieval plots not shown), consistent with expected pollution particles in this region. Even with $558 \mathrm{~nm}$ AOD approaching 0.5 , the algorithm is able to separate the surface from the atmosphere, as shown across the first row of Fig. 2. Qualitatively, the MODIS OC and MISR RA AOD and $R_{\mathrm{rs}}$ agree well with each other, although MODIS suggests that the aerosol might be a bit smaller than the RA reports (panel $b$ compared to panel f) and that the water might be a little less green (panel c compared to panel g). Although the MISR RA AOD in panel (a) does not appear to be correlated with the water color seen in panel (d), indicating successful surfaceatmosphere separation, it does appear as though retrieved ANG might be biased a bit low in the turbid-water regions (discussed further in Sect. 4 below). AOD and ANG retrieved from the MISR RA and MISR SA agree extremely well with each other, even though the comparisons are confined to the non-turbid-water regions of the scene where the SA provides coverage. Again, this figure illustrates how the MISR RA atmospheric correction allows for increased $R_{\mathrm{rS}}$ coverage over near-coastal water.

Figure 3 shows results for the eutrophic northern Caspian Sea on 19 September 2015. The RA (panel b) indicates that a plume comprised of small (ANG 1.5), spherical non-absorbing (shape and light-absorption retrieval plots not shown) aerosol is present over a $\sim 20000 \mathrm{~km}^{2}$ region in the north-central part of the plotted domain. Within the plume, the RA indicates that the mid-visible AOD varies between 0.10 and 0.15 , whereas outside the plume the retrieved AOD is $\sim 0.05$. This skill in identifying relatively low AOD plumes over bright water is due to the multiple view angles provided by MISR. Because the portion of TOA reflectance attributed to the retrieved $R_{\mathrm{rs}}$ decreases with increasing view angle, the spatial pattern of the MISR Df $\left(70^{\circ}\right.$ forward view angle) NIR reflectance (panel k) correlates well with the retrieved AOD (panel a). Although the MISR RA shows skill in separating the effects of atmospheric and oceanic scattering, Fig. $3 b$ and d suggest some surface artifacts might be aliasing the ANG retrieval. That said, the artifacts still do not lead to substantially different AOD retrievals between the darkwater and eutrophic-water portions of the scene. MODIS actually masks much of the eutrophic region for this scene, with large discrepancies found between the MISR RA and MODIS for the remaining portions. The MISR SA does not report any aerosol retrievals over water in this region, probably due to shallow-water masking.

In Figs. 4 and 5 we present results from the MISR RA, MODIS OC algorithm, and the MISR SA for the eastern Yellow Sea region on 13 March 2012. Note that although AERONET data are plotted for this region, results over land may not be representative of the air column over nearby ocean, particularly if the AERONET station is elevated. Fig- 


\section{Complex water retrieval: Yellow Sea, 3/13/2012, Terra Orbit 65076}

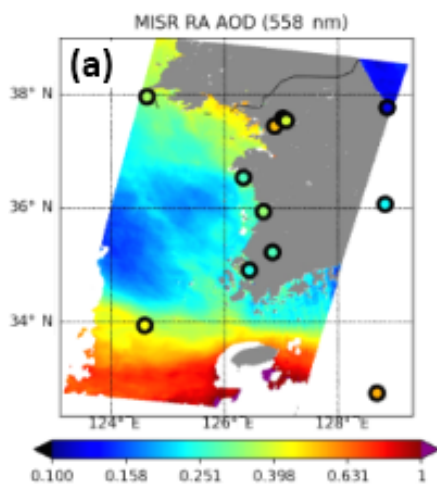

MODIS Terra OC AOD (558 $\mathrm{nm})$
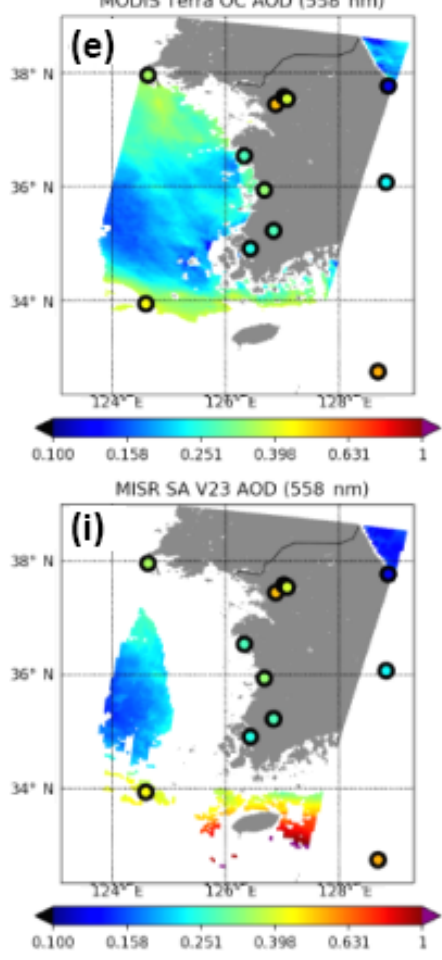
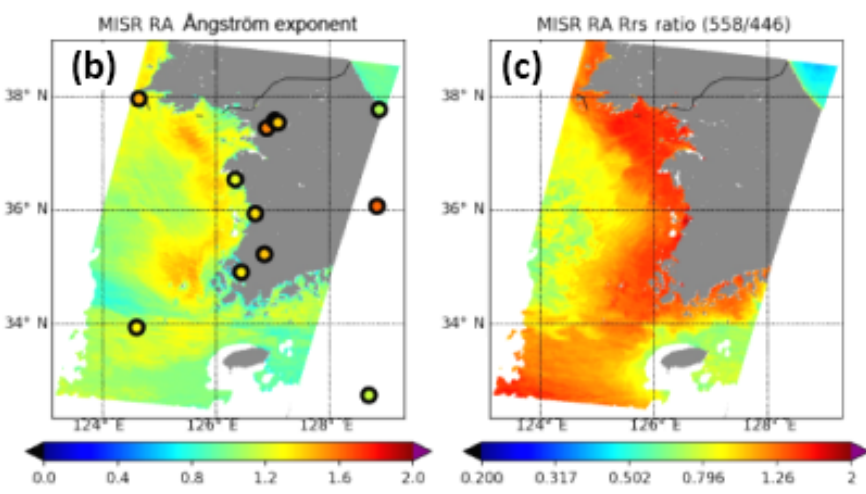

MODIS Terra OC Angstrom exponent

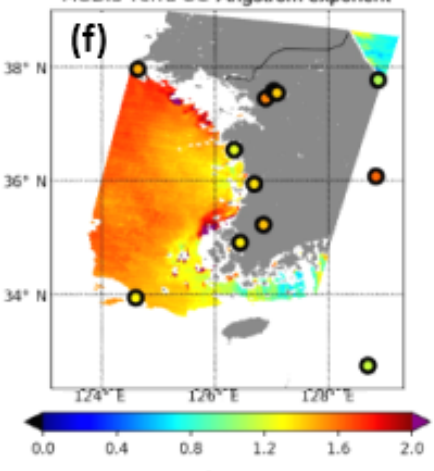

MISR SA V23 Angström exponent

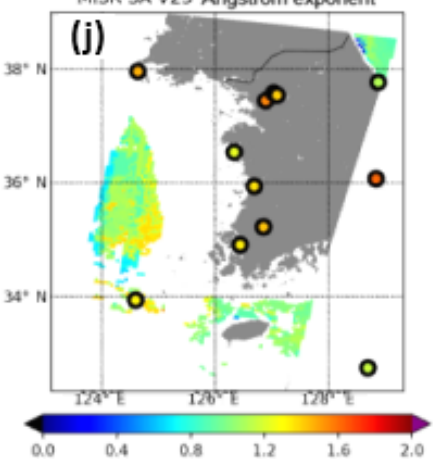

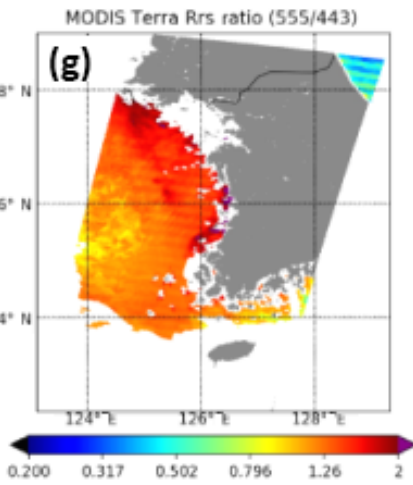

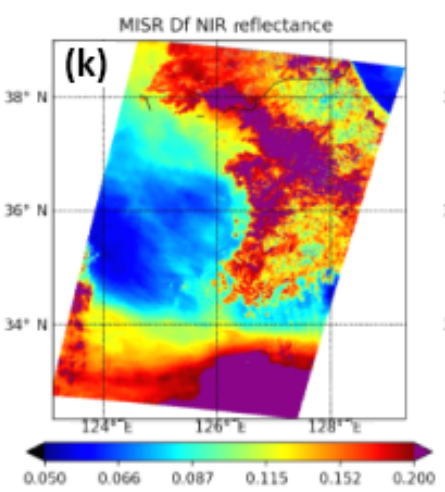

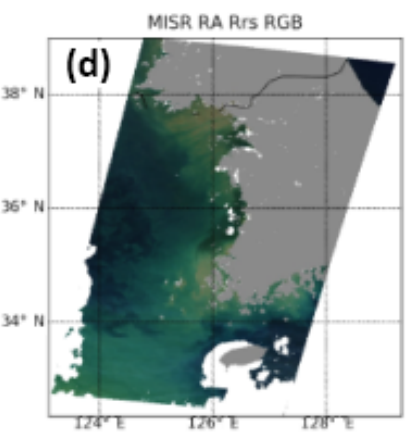
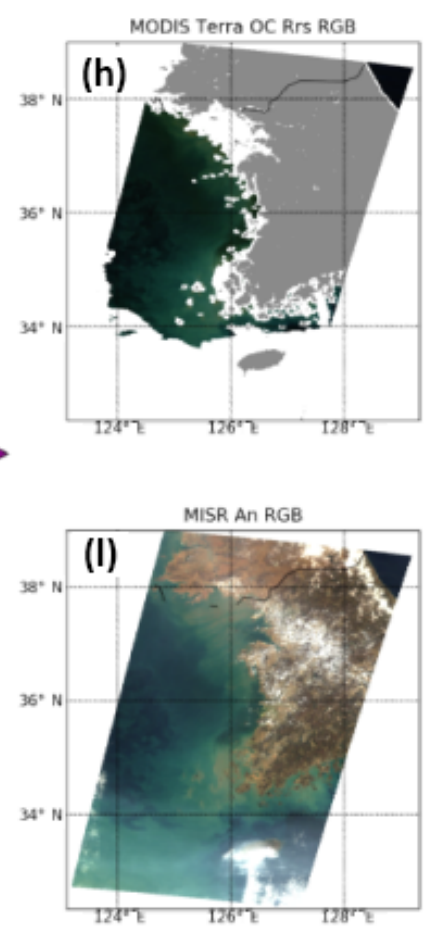

Figure 4. Same as Fig. 1, except for the optically diverse waters of the Yellow Sea. MISR imagery acquired on 13 March 2012, 02:30Z: Terra Orbit 65076, blocks 60-64. Coincident AERONET data were acquired as part of the Southeast-Asian leg of the DRAGON field campaign (colored circles). As most AERONET data are taken over land (some elevated), the data are not necessarily representative of the adjacent oceanic air column.

ure $4 \mathrm{a}$ and e show good AOD agreement between the MISR RA and MODIS, although panels (b) and (f) indicate rather large discrepancies in ANG between the two retrievals.

Although AERONET data from the DRAGON deployment in Southeast Asia show variability in ANG ( 1.1-1.5), MISR ANG appears low-biased and MODIS ANG appears slightly high-biased. Not surprisingly, this discrepancy between MISR and MODIS ANG shows up in the $R_{\mathrm{rs}}$ ratios (panels $\mathrm{c}$ and g, respectively). Note that in the southwest corner the of the scene, where the MISR RA retrieves AOD of up to $\sim 1$, the MISR RA is still capable of retrieving wa- ter color (panels d and 1), whereas MODIS does not provide results for this part of the scene. In Fig. 5, we present the MISR-retrieved $R_{\mathrm{rs}}$ RGB for this scene juxtaposed with a Rayleigh-corrected MISR nadir true-color image and the MODIS-retrieved $R_{\mathrm{rs}}$ RGB.

Additional examples are included in the Supplement: a biological bloom in the eastern Argentine Sea and three cases over the Bohai Sea along coastal China east of Beijing, showing results for low, moderate, and high AOD loading. 


\section{Complex water retieval:}

MISR-RA-retrieved $\mathrm{R}_{\mathrm{rs}}$

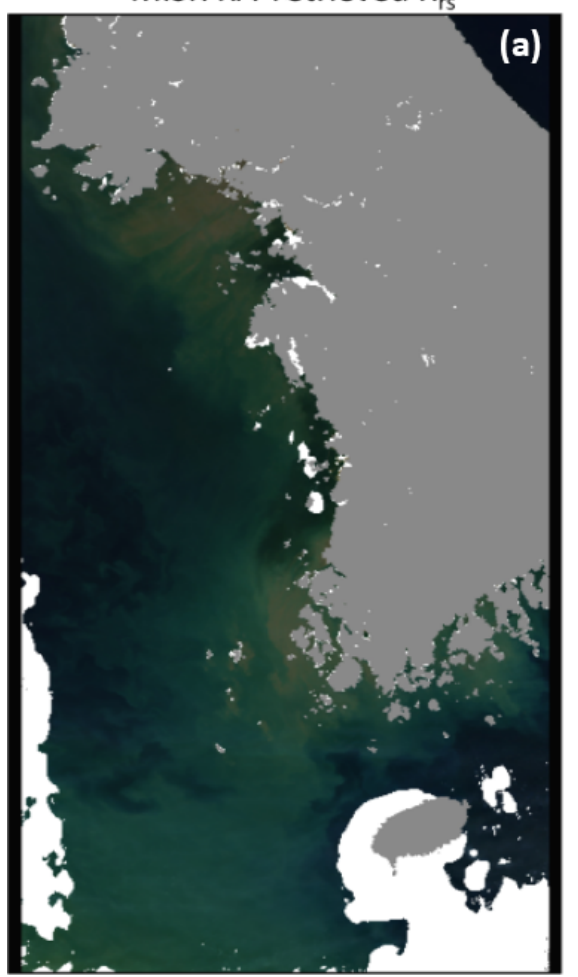

Yellow Sea, 3/13/2012, Terra Orbit 65076

MISR An true color image

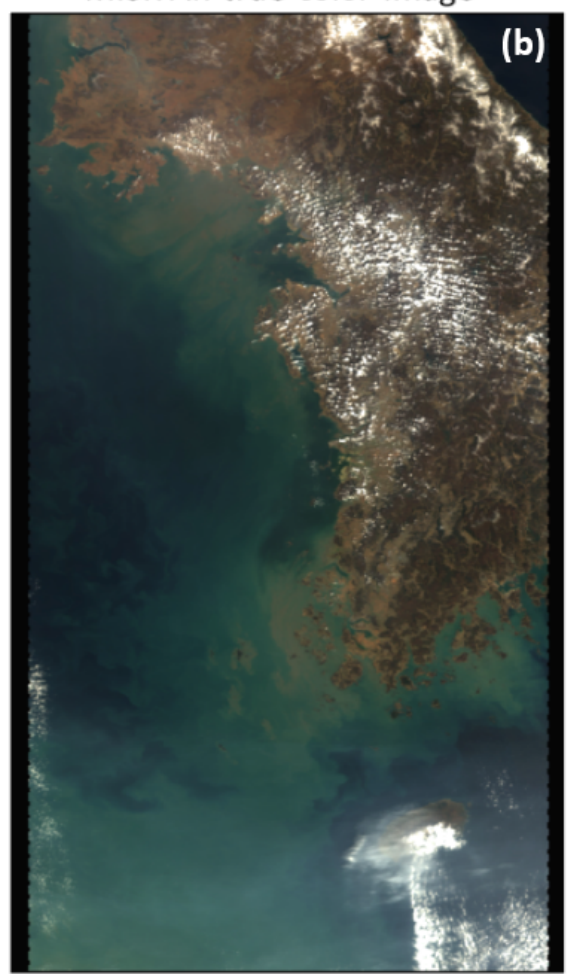

MODIS-retrieved $\mathrm{R}_{\mathrm{rs}}$

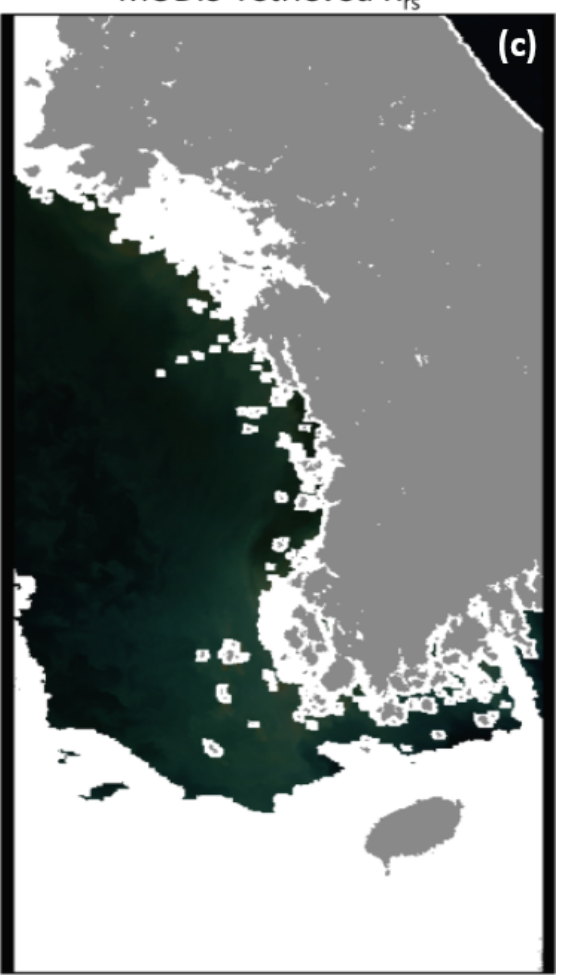

Figure 5. MISR (and MODIS) retrieval imagery acquired on 13 March 2012, 02:30 Z: Terra Orbit 65076, blocks 60-64. RGB images have been brightness-enhanced. Panel (b) represents the MISR An true-color Rayleigh-corrected RGB for the scene. Panel (a) represents the MISR-RA-retrieved $R_{\mathrm{rs}}$ RGB image, and panel (c) represents the MODIS-retrieved $R_{\mathrm{rs}}$ RGB image.

\section{Statistical validation of the MISR over-water RA AOD and ANG using AERONET}

As in Limbacher and Kahn (2017), MISR RA aerosol retrievals are performed at $1.1 \mathrm{~km}$ resolution. The newly released MISR V23 aerosol product now reports AOD and aerosol properties at $4.4 \mathrm{~km}$ resolution, a major improvement compared with the $17.6 \mathrm{~km}$ resolution for version 22 (Garay et al., 2017). For validation against AERONET, we average all good-quality MISR $1.1 \mathrm{~km}$ retrievals surrounding the AERONET site, yielding one value per coincidence. We consider AERONET and MISR coincidences only if the following conditions are met.

- At least one AERONET observation on each side of the temporal averaging window $( \pm 30 \mathrm{~min}$ of MISR overpass).

- AERONET temporal variability (max-min for all four MISR bands) $<0.05+0.1 \cdot$ AOD .

- AERONET reported elevation $<100 \mathrm{~m}$. This is necessary for two reasons:
- AERONET AOD (and ANG) might otherwise not be comparable to our over-water retrievals (ocean retrievals are all at sea level).

- The LUT we use (for water retrievals only) contains only one surface pressure value (1013.25 mbar), meaning that retrievals over elevated inland lakes could suffer from non-negligible errors, depending on elevation.

- At least $5 \%$ of MISR observations within $25 \mathrm{~km}$ of the AERONET site result in good-quality MISR overwater aerosol retrievals. A good-quality MISR aerosol retrieval requires all the following pixel-level criteria to be met (most of which are for cloud screening):

- MISR RA cost function $(M)<1$, which indicates a good model fit to the observations.

- MISR RA maximum channel-specific cost function $<0.5$, to screen out clouds that might only be visible in one or two cameras.

- MISR RA $M / M^{\prime \prime}<10^{-3}$, as this ratio tends to increase when clouds are present.

- Additionally, to improve cloud detection, we flag all MISR retrievals immediately surrounding any 
MISR-AERONET comparison: Dunkerque, 1/29/2015
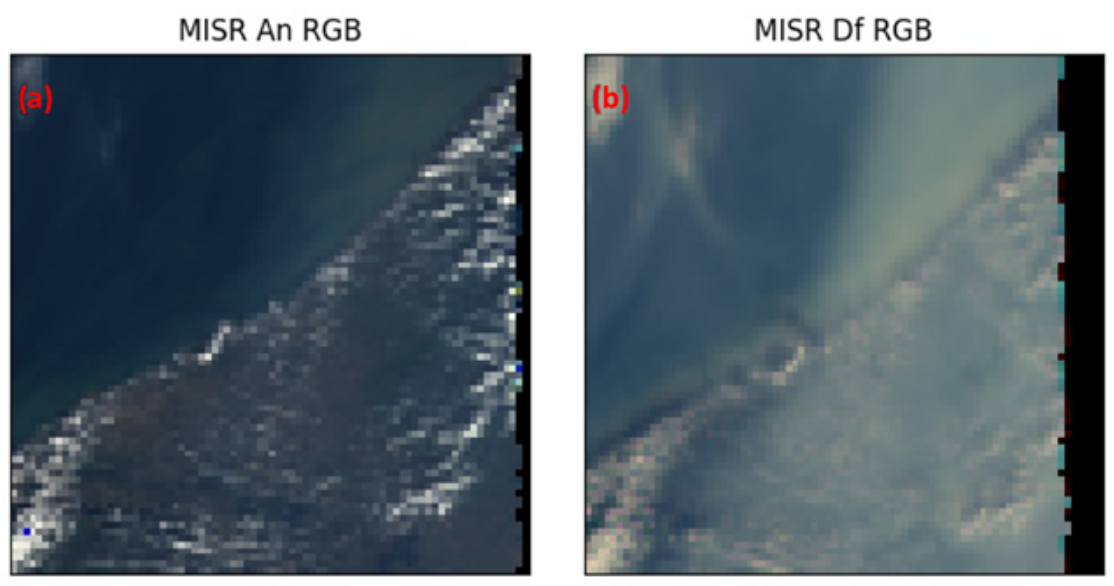

MISR RA Rrs RGB

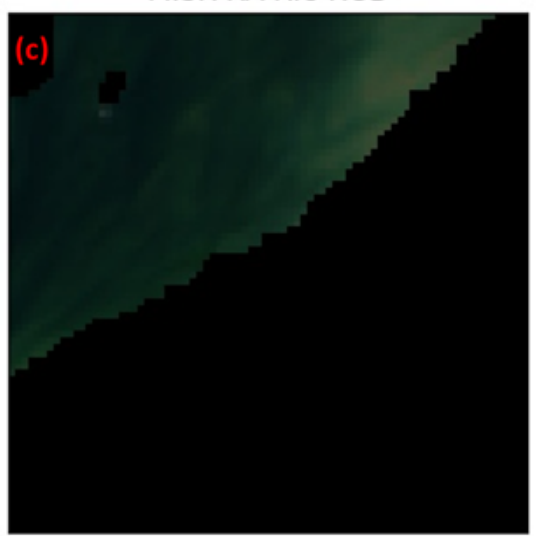

MISR RA aerosol optical depth $(558 \mathrm{~nm})$

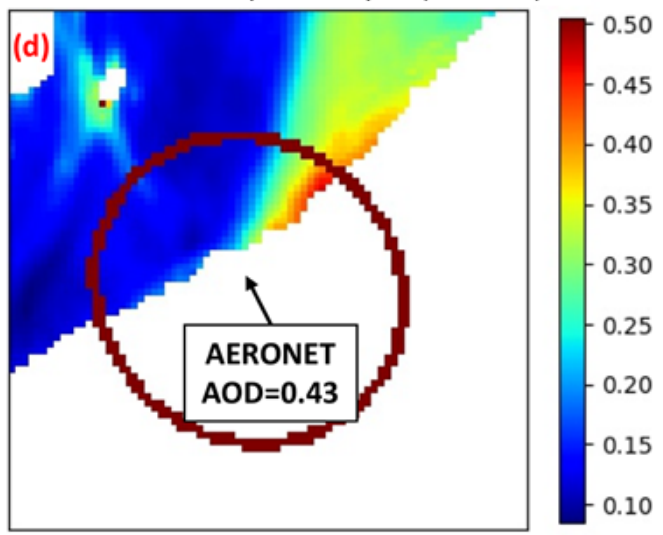

Figure 6. Example set of $80 \times 80$ pixel MISR aerosol retrievals centered over the Dunkerque AERONET site on 29 January 2015, showing the effects of scene variability on the MISR-AERONET comparison. Brightness-enhanced true-color images for the (a) nadir and (b) $70.5^{\circ}$ forward camera. (c) Brightness-enhanced true-color image of MISR-RA-retrieved $R_{\mathrm{rs}}$ and (d) MISR-RA-retrieved over-water AOD. The red circle in panel (d) represents the $25 \mathrm{~km}$ averaging window used for MISR and AERONET comparisons. The \pm 30 min average AERONET $558 \mathrm{~nm}$ (interpolated) AOD is provided for context. Cloud-land masking has been applied to panels (c) and (d).

pixel whose aerosol retrieval does not meet the three quality thresholds outlined above.

These constraints yield 2419 MISR-AERONET coincidences for the 4 years of MISR data we currently have processed (4 years interspersed between September 2000 and November 2016).

Results from the statistical comparison of MISR and AERONET are shown in Tables 1 and 2 (558 nm AOD and ANG, respectively). In order to identify co-variation between retrieved surface albedo and aerosol properties, we perform the following comparisons for both AOD and ANG against AERONET:

- Average - average all good-quality MISR aerosol retrievals within $25 \mathrm{~km}$ of the AERONET site.

- Lowest $10 \%$ - average only those good-quality MISR aerosol retrievals where the retrieved $558 \mathrm{~nm}$ (green)
$R_{\mathrm{rs}}$ is lower than the 10th percentile value for that specific scene.

- Highest $10 \%$ - average only those good-quality MISR aerosol retrievals where the retrieved $558 \mathrm{~nm}$ (green) $R_{\mathrm{rs}}$ is higher than the 90th percentile value for that specific scene.

Figure 6 illustrates how the data are parsed and averaged; it provides some context for the AOD and ANG scatterplots presented in Fig. 7, which shows both scene-averaged values for ANG and AOD in addition to 2-D histograms of AOD and ANG errors as a function of water color. We create the following productivity and turbidity index (PTI) that allows us to characterize MISR retrieval errors against a single watercolor parameter (similar to the normalized difference vegetation index, NDVI, over land):

$$
\mathrm{PTI}=\frac{\text { MISR }[\text { Green }+ \text { Red }+ \text { NIR }] R_{\mathrm{rs}}-\text { MISR Blue } R_{\mathrm{rs}}}{\text { MISR } R_{\mathrm{rs}} \text { Spectral Sum }} .
$$


Table 1. Statistics of MISR $558 \mathrm{~nm}$ (Green) AOD retrievals as compared to AERONET.

\begin{tabular}{lrrrrrr}
\hline $0.00<$ AERONET AOD $<1.00$ & $r$ & MAE & RMSE & Bias & 0.03 or $10 \%$ & Number \\
\hline Average $(<25 \mathrm{~km})$ & 0.954 & 0.018 & 0.038 & 0.006 & 0.717 & 2419 \\
Lowest $10 \% R_{\mathrm{rs}}(<25 \mathrm{~km})$ & 0.938 & 0.021 & 0.044 & 0.010 & 0.649 & 2419 \\
Highest $10 \% R_{\mathrm{rs}}(<25 \mathrm{~km})$ & 0.949 & 0.020 & 0.041 & 0.010 & 0.678 & 2419 \\
\hline $0.00<$ AERONET AOD $<0.10$ & $r$ & MAE & RMSE & Bias & 0.03 or $10 \%$ & Number \\
\hline Average $(<25 \mathrm{~km})$ & 0.654 & 0.015 & 0.024 & 0.010 & 0.818 & 1202 \\
Lowest $10 \% R_{\mathrm{rs}}(<25 \mathrm{~km})$ & 0.573 & 0.017 & 0.032 & 0.015 & 0.735 & 1202 \\
Highest $10 \% R_{\mathrm{rs}}(<25 \mathrm{~km})$ & 0.641 & 0.016 & 0.027 & 0.012 & 0.780 & 1202 \\
\hline
\end{tabular}

In this table, $r$ is the Pearson correlation coefficient, MAE is the median absolute error, RMSE is the root-mean-square error between the satellite retrieval and AERONET, bias is the mean MISR-AERONET value, 0.03 or $10 \%$ represents the fraction of MISR retrievals falling within the maximum of 0.03 or $10 \%$ of the AERONET AOD, and number is the number of validation cases included. In the first column, average refers to using the average MISR retrieval value (good quality) over all retrievals within $25 \mathrm{~km}$ of the AERONET site, the lowest $10 \% R_{\mathrm{rs}}$ refers to using only the pixels with $R_{\mathrm{rs}}$ (green band only) lower than the 10th percentile values (for a given cloud-screened scene) for comparison with AERONET, and the highest $10 \% R_{\mathrm{rs}}$ refers to using only the retrievals with the $10 \%$ largest $R_{\mathrm{rs}}$ for comparison with AERONET.

Table 2. Statistics of MISR ANG retrievals as compared to AERONET.

\begin{tabular}{lrrrrl}
\hline $0.00<$ AERONET AOD $<1.00$ & $r$ & MAE & RMSE & Bias & Number \\
\hline Average $(<25 \mathrm{~km})$ & 0.662 & 0.250 & 0.416 & -0.133 & 2419 \\
Lowest $10 \% R_{\mathrm{rs}}(<25 \mathrm{~km})$ & 0.643 & 0.257 & 0.416 & -0.112 & 2419 \\
Highest $10 \% R_{\mathrm{rs}}(<25 \mathrm{~km})$ & 0.640 & 0.274 & 0.439 & -0.180 & 2419 \\
\hline $0.20<$ AERONET AOD $<1.00$ & $r$ & MAE & RMSE & Bias & Number \\
\hline Average $(<25 \mathrm{~km})$ & 0.890 & 0.169 & 0.250 & -0.025 & 502 \\
Lowest $10 \% R_{\mathrm{rs}}(<25 \mathrm{~km})$ & 0.885 & 0.173 & 0.252 & -0.003 & 502 \\
Highest $10 \% R_{\mathrm{rs}}(<25 \mathrm{~km})$ & 0.861 & 0.194 & 0.282 & -0.060 & 502 \\
\hline
\end{tabular}

In this table, the statistical parameters (e.g., RMSE) are defined the same way as in Table 1.

Note that PTI is not retrieved, rather it is calculated from the retrieved spectral remote-sensing reflectances. Figure $6 \mathrm{~b}$ combined with Fig. 6d illustrate a limitation of our cloud screening, as we clearly fail to screen all the clouds in the upper-left portion of the plots. Additionally, the large AOD variability found within the $25 \mathrm{~km}$ averaging window suggests that some of the difference between AERONET and MISR (Fig. 7 and Tables 1 and 2) is likely related to scene spatial variability, combined with the differences in MISR and AERONET spatial-temporal sampling, a conclusion reached in earlier research as well (Kahn et al., 2010).

Figure $7 \mathrm{a}, \mathrm{c}$ and Table 1 demonstrate the ability of the MISR RA to retrieve AOD under a variety of conditions: low AOD; high AOD; and over oligotrophic, eutrophic, shallow, and turbid water. Specifically, Fig. 7c illustrates the general insensitivity of retrieved AOD to water color. This is further demonstrated by the eight color patches at the top of Fig. $7 \mathrm{c}$ and d. They present the averaged MISR-RA-retrieved $R_{\mathrm{rs}}$ values (made into RGB images and enhanced by $10 \mathrm{x}$ in brightness) for the corresponding PTI range along the $x$ axis of the panel. For PTI $\sim-1$, the water is oligotrophic, and its color is blue. As PTI increases to values between about 0 and 0.5 , the water tends toward eutrophic and begins to appear green. As PTI exceeds about 0.75 , the water appears more brown than green and would likely be classified as turbid.

Table 1 appears to confirm the insensitivity of retrieved AOD to water color, as the AOD statistics from the darkest waters of the scene are nearly identical to those over the brightest waters. We expect brighter, more productive waters near the coast, where AERONET stations are preferentially located. The average bright-water retrieval was performed an average of $17.3 \mathrm{~km}$ from the AERONET location; the dark(er)-water retrievals were performed $19.8 \mathrm{~km}$ from AERONET on average, i.e., generally including darker water farther from the coast. So the darker-water retrievals are more likely to encompass a gradient in aerosol amount. This might explain why Table 1 seems to indicate that at low AOD the brighter albedo retrievals tend to perform better than the lower $R_{\mathrm{rs}}$ retrievals. Overall, $72 \%$ of aerosol retrievals fall within the maximum of $0.03 \%$ or $10 \%$ of the AERONET AOD value. Figure $7 \mathrm{a}, \mathrm{c}$ and Table 1 indicate that the MISR RA is quite capable of retrieving good-quality AODs over scenes that would challenge many other aerosol retrieval algorithms.

In Fig. 7b, d and Table 2, we compare ANG results from the MISR RA to those calculated from AERONET AODs, 

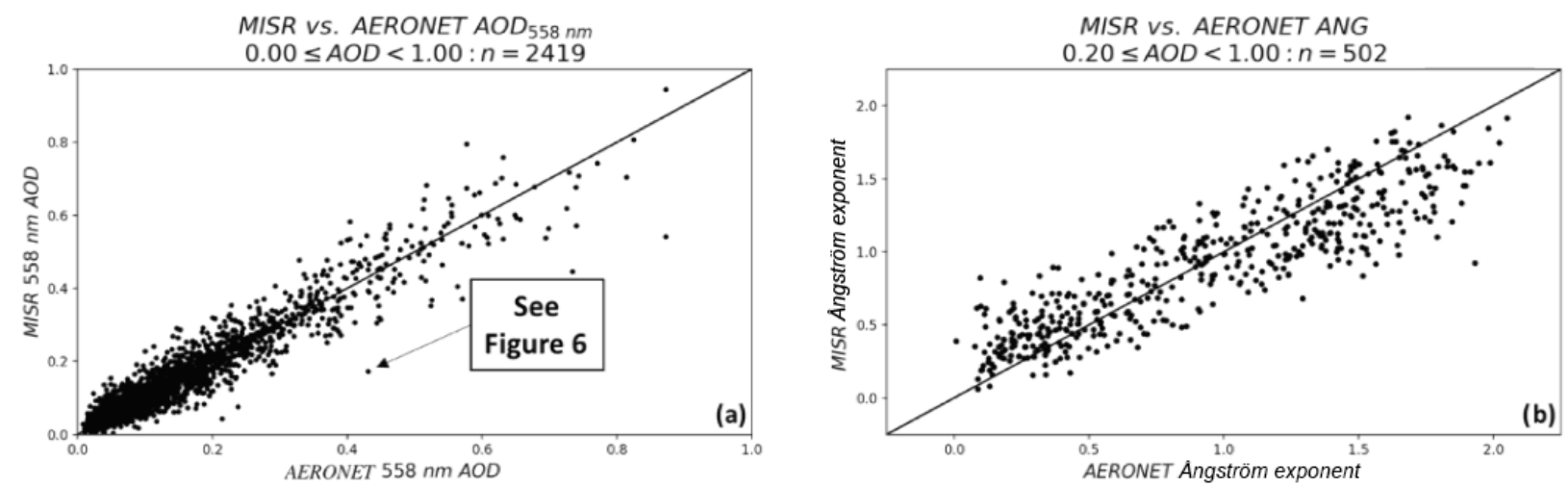

MISR - AERONET AOD $558 \mathrm{~nm}$ VS. MISR-retrieved PTI $0.00 \leq A O D<1.00: n=1281237$
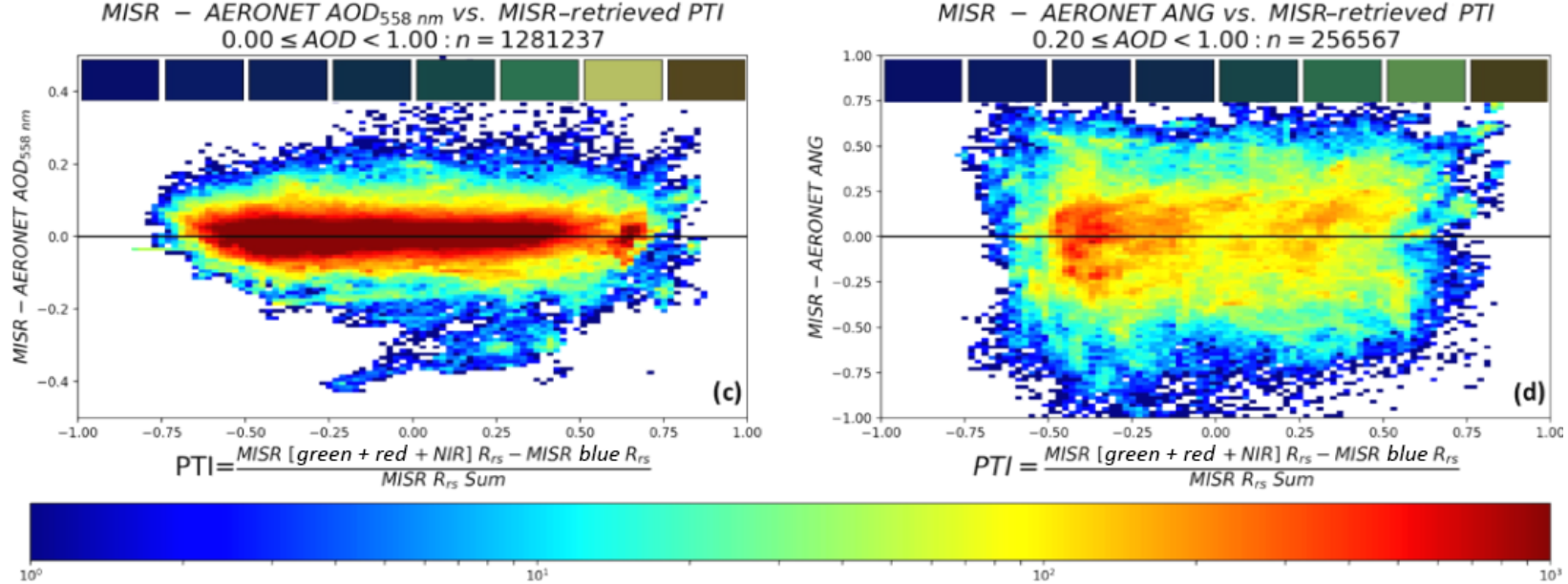

Figure 7. MISR vs. AERONET AOD and ANG statistical comparisons for all cloud-screened coincidences. (a) MISR vs. AERONET green-band $(558 \mathrm{~nm}$, interpolated for AERONET) AOD data; (b) MISR vs. AERONET ANG data, conditioned on AERONET 558 nm AOD $>0.20$. (c) Two-dimensional histogram of all MISR-AERONET AOD differences vs. MISR-retrieved PTI (Eq. 8). For this panel (and d), we compare all cloud-free MISR data to AERONET, meaning there can be over 1000 MISR-AERONET data points for each unique AERONET observation. (d) Two-dimensional histogram of all MISR-AERONET ANG differences vs. MISR-retrieved PTI (Eq. 8). For this panel (and d), we compare all cloud-free MISR data to AERONET, meaning there can be over 1000 MISR-AERONET data points for each unique AERONET observation. For panels (c) and (d), the eight colored rectangular boxes represent the averaged MISR-RA-retrieved $R_{\mathrm{rs}}$ values (brightness enhanced by 10x and made into RGB images) over the $x$-axis range that they physically intersect in the plots.

for scenes where the AERONET $558 \mathrm{~nm}$ AOD $>0.20$. Because ANG is more meaningful as AOD increases, it is more difficult to assess the sensitivity of RA-retrieved ANG to RAretrieved surface albedo, as there are only 502 coincidences for AOD $>0.20$ in the validation dataset. Nevertheless, it does appear as though the uncertainty of RA-retrieved ANG increases as the water becomes greener (or more turbid). This can be seen qualitatively in Fig. $7 \mathrm{~d}$ based on increased scatter density with increasing PTI and quantitatively by comparing the bright with the dark-water retrievals in Table 2. Some of this might be due to the limited range of light-absorbing particle properties in the current algorithm climatology (Kahn et al., 2010; Limbacher and Kahn, 2014). Still, with a linear correlation coefficient of 0.89 and a root-mean-square error (RMSE) of 0.25, the current MISR RA provides some quantitative information about particle size.

\section{Conclusions}

In Limbacher and Kahn (2017), we demonstrated results from an upgraded MISR research aerosol retrieval algorithm (RA) that allows us to derive chlorophyll $a$ concentration from MISR over case I waters. We also presented modifications to a stray-light correction algorithm first detailed in Limbacher and Kahn (2015) and identified (and corrected) temporal trends in the MISR radiometric calibration. Here, after applying those corrections to the MISR top-ofatmosphere radiances, we upgrade and extend the MISR RA for use over turbid, shallow, and eutrophic waters. By assuming the waterbody reflectance can be modeled adequately as a Lambertian reflector, this upgraded $1.1 \mathrm{~km}$ resolution retrieval algorithm self-consistently retrieves AOD, aerosol type, and ocean surface remote-sensing reflectance $\left(R_{\mathrm{rS}}\right)$.

We (i) introduce a productivity and turbidity index (PTI), calculated from retrieved spectral $R_{\mathrm{rs}}$, that distinguishes 
water types (similar to NDVI over land) and (ii) validate the upgraded RA statistically by comparing the MISRretrieved spectral AOD and Ångström exponent (ANG) against 2419 cloud-screened coincident direct-Sun observations from AERONET. We also compare MISR RA results with those from the MODIS ocean color algorithm (OC) and the MISR standard aerosol retrieval algorithm (SA) for several turbid-, shallow-, and eutrophic-water cases. Results indicate that the MISR RA has sensitivity to both AOD and ANG, even over bright waters, and typically outperforms the MODIS OC and MISR SA in coverage, or in accuracy compared to expectation. For mid-visible AOD retrieved under all conditions, we report a root-mean-square error (RMSE) of 0.038 and a linear-correlation coefficient $(r)$ of 0.95 . For the 502 scenes where AERONET AOD $>0.20$, we report an ANG RMSE of 0.25 and $r$ of 0.89 . Although AOD results do not appear to be substantially affected by water color, uncertainty associated with our ANG retrievals appears to increase as the water "greens" (or "browns").

The atmospheric correction needed to obtain accurate surface reflectance retrievals should be much more robust from the MISR multi-angle instrument than from single-view instruments such as MODIS. As such, MISR data could be used to make substantial contributions to the ocean color community. This is especially true in regions of shallow, turbid, and eutrophic waters, locations where aerosol retrieval algorithms for single-view instruments tend to be underdetermined, yet waters tend to be more biologically productive than the oligotrophic waters where single-view retrievals perform best. Therefore, a next step forward from this work would be to use the MISR RA to constrain the atmosphericcorrection algorithm used by the ocean color community for OC retrievals, possibly extrapolated in space and time when applied to single-view instruments that offer greater coverage and include spectral bands optimized for ocean color retrievals. We hope this will result in more robust and numerous OC retrieval results over biologically productive coastal waters and major aerosol transport pathways over ocean.

Data availability. Data are available at http://www.remss.com/ (last access: 23 January 2019, https://doi.org/10.5067/TERRA/ MISR/MIANCAGP_Ancillary.001; MISR Science Team, 2015a, https://doi.org/10.5067/Terra/MISR/MI1B2E_L1.003; MISR Science Team, 2015b, https://doi.org/10.5067/Terra/MISR/ MIB2GEOP_L1.002; MISR Science Team, 2015c, https://doi.org/ 10.5067/Terra/MISR/MI1B2T_L1.003; MISR Science Team, 2015d, https://doi.org/10.5067/Terra/MISR/MIL2ASAE_L2.002; MISR Science Team, 2015e).

Supplement. The supplement related to this article is available online at: https://doi.org/10.5194/amt-12-675-2019-supplement.
Author contributions. Originally developed by RAK, the MISR RA has been a joint effort of JAL and RAK since early 2011. The updated algorithm was developed by JAL (with supervision from RAK), while the manuscript was produced with input from both parties.

Competing interests. The authors declare that they have no conflict of interest.

Acknowledgements. We thank Chris Proctor and NASA's Ocean Biology Processing Group for providing the MODIS-Terra ocean color products. We thank our colleagues on the Jet Propulsion Laboratory's MISR instrument team and at the NASA Langley Research Center's Atmospheric Sciences Data Center for their roles in producing the MISR standard datasets, as well as Brent Holben at the NASA Goddard Space Flight Center and the AERONET team for producing and maintaining this critical validation dataset. CCMP version 2.0 vector wind analyses are produced by Remote Sensing Systems. This research is supported in part by NASA's Climate and Radiation Research and Analysis Program under Hal Maring, as well as NASA's Atmospheric Composition Program under Richard Eckman.

Edited by: Alexander Kokhanovsky

Reviewed by: three anonymous referees

\section{References}

Ahmad, Z., Franz, B., McClain C., Kwiatkowska, E., Werdell, J., Shettle, E., and Holben, B.: New aerosol models for the retrieval of aerosol optical thickness and normalized water-leaving radiances from the SeaWiFS and MODIS sensors over coastal regions and open oceans, Appl. Optics, 49, 5545-5560, 2010.

Atlas, R., Hoffman, R. N., Ardizzone, J., Leidner, S. M., Jusem, J. C., Smith, D. K., and Gombos, D.: A cross-calibrated, multiplatform ocean surface wind velocity product for meteorological and oceanographic applications, B. Am. Meteorol. Soc., 92, 157174, https://doi.org/10.1175/2010BAMS2946.1, 2011.

Bailey, S., Franz, B., and Werdell, J.: Estimation of near-infrared water-leaving reflectance for satellite ocean color data processing, Opt. Express, 18, 7521-7527, 2010.

Bauer, J., Cai, W.-J., Raymond, P., Bianchi, T., Hopkinson, C., and Regnier, P.: The changing carbon cycle of the coastal ocean, Nature, 504, 61-70, https://doi.org/10.1038/nature12857, 2013.

Behrenfeld, M. J., Boss, E., Siegel, D. A., and Shea, D. M.: Carbon-based ocean productivity and phytoplankton physiology from space, Global Biogeochem. Cy., 19, GB1006, https://doi.org/10.1029/2004GB002299, 2005.

Diner, D., Beckert, J., Reilly, T., Bruegge, C., Conel, J., Kahn, R., Martonchik, J., Ackerman, T., Davies, R., Gerstl, S.,Gordon,H., Muller, J., Myneni, R., Sellers, P., Pinty, B., and Verstraete, M.: Multi-angle Imaging SpectroRadiometer (MISR) instrument description and experiment overview, IEEE T. Geosci. Remote Sens., 36, 1072-1087, https://doi.org/10.1109/36.700992, 1998.

Diner, D. J., Abdou, W. A., Ackerman, T. P., Crean, K., Gordon, H. R., Kahn, R. A., Martonchik, J. V., Paradise, S. R., Pinty, B., Ver- 
straete, M. M., Wang, M., and West, R. A.: Multi-Angle Imaging SpectroRadiometer Level 2 Aerosol Retrieval Algorithm Theoretical Basis, Revision G, JPL D-11400, Jet Propulsion Laboratory, California Institute of Technology, Pasadena, 2008.

Dubovik, O. and King, M. D.: A flexible inversion algorithm for retrieval of aerosol optical properties from Sun and sky radiance measurements, J. Geophys. Res., 105, 20673-20696, 2000.

Dubovik, O., Sinyuk, A., Lapyonok, T., Holben, B. N., Mishchenko, M., Yang, P., Eck, T. F., Volten, H., Munoz, O., Veihelmann, B., van der Zande, W. J., Leon, J.-F., Sorokin, M., and Slutsker, I.: Application of spheroid models to account for aerosol particle nonsphericity in remote sensing of desert dust, J. Geophys. Res., 111, D11208, https://doi.org/10.1029/2005JD006619, 2006.

Eck, T. F., Holben, B. N., Reid, J. S., Dubovik, O., Smirnov, A., O'Neill, N. T., Slutsker, I., and Kinne, S.: Wavelength dependence of the optical depth of biomass burning, urban, and desert dust aerosols, J. Geophys. Res., 104, 31333-31349, https://doi.org/10.1029/1999JD900923, 1999.

Garay, M. J., Kalashnikova, O. V., and Bull, M. A.: Development and assessment of a higher-spatial-resolution $(4.4 \mathrm{~km})$ MISR aerosol optical depth product using AERONETDRAGON data, Atmos. Chem. Phys., 17, 5095-5106, https://doi.org/10.5194/acp-17-5095-2017, 2017.

Gordon, H. R. and Wang, M.: Retrieval of water-leaving radiance and aerosol optical thickness over oceans with SeaWiFS: a preliminary algorithm, Appl. Optics, 33, 443-452, 1994.

Heukelem, L. V., Thomas, C. S., and Glibert, P. M.: Sources Of Variability In Chlorophyll Analysis By Fluorometry And High Performance Liquid Chromatography In a SIMBIOS InterCalibration Exercise, NASA TM 2002-02338-0, NASA Goddard Space Flight Center, 2002.

Holben, B. N., Eck, T. F., Slutsker, I., Tanre, D., Buis, J. P., Sezter, A., Vermote, E., Reagan, J. A., Kaufman, Y. J., Nakajima, T., Lavenu, F., Jankowiak, I., and Smirnov, A.: AERONET - a federated instrument network and data archive for aerosol characterization, Remote Sens. Environ., 66, 1-16, 1998.

Holben, B. N., Eck, T. F., Slutsker, I., Smirnov, A., Sinyuk, A., Schafer, J., Giles, D., and Dubovik, O.: Aeronet's Version 2.0 quality assurance criteria, Proc. SPIE 6408, Remote Sensing of the Atmosphere and Clouds, 64080Q, https://doi.org/10.1117/12.706524, 2006.

$\mathrm{Hu}, \mathrm{C}$., Lee, Z., and Franz, B.: Chlorophyll-a algorithms for oligotrophic oceans: A novel approach based on threeband reflectance difference, J. Geophys. Res., 117, C01011, https://doi.org/10.1029/2011JC007395, 2012.

Kahn, R. A. and Gaitley, B. J.: An analysis of global aerosol type as retrieved by MISR, J. Geophys. Res.-Atmos., 120, 4248-4281, https://doi.org/10.1002/2015JD023322, 2015.

Kahn, R. A., Sayer, A. M., Ahmad, Z., and Franz, B.: How Aerosol Amount and Type Affect SeaWiFS Ocean Color Retrievals, J. Atmos. Ocean Tech., 33, 1185-1209, https://doi.org/10.1175/JTECH-D-15-0121.1, 2016.

Kahn, R. A., Gaitley, B. J., Garay, M. J., Diner, D. J., Eck, T. F., Smirnov, A., and Holben, B. N.: Multiangle Imaging SpectroRadiometer global aerosol product assessment by comparison with the Aerosol Robotic Network, J. Geophys. Res., 115, D23209, https://doi.org/10.1029/2010JD014601, 2010.

Lee, Z., Wei, J., Voss, K., Lewis, M., Bricaud, A., and Huot, Y.: Hyperspectral absorption coefficient of "pure" seawater in the range of 350-550 $\mathrm{nm}$ inverted from remote sensing reflectance, Appl. Optics, 54, 546-558, 2015.

Limbacher, J. A. and Kahn, R. A.: MISR research-aerosolalgorithm refinements for dark water retrievals, Atmos. Meas. Tech., 7, 3989-4007, https://doi.org/10.5194/amt-7-3989-2014, 2014.

Limbacher, J. A. and Kahn, R. A.: MISR empirical stray light corrections in high-contrast scenes, Atmos. Meas. Tech., 8, 29272943, https://doi.org/10.5194/amt-8-2927-2015, 2015.

Limbacher, J. A. and Kahn, R. A.: Updated MISR dark water research aerosol retrieval algorithm - Part 1: Coupled $1.1 \mathrm{~km}$ ocean surface chlorophyll $a$ retrievals with empirical calibration corrections, Atmos. Meas. Tech., 10, 1539-1555, https://doi.org/10.5194/amt-10-1539-2017, 2017.

Maritorena, S., Siegel, D., and Peterson, A.: Optimization of a semianalytical ocean color model for global-scale applications, Appl. Optics, 41, 2705-2714, 2002.

Martonchik, J. V., Kahn, R. A., and Diner, D. J.: Retrieval of Aerosol Properties over Land Using MISR Observations, in: Satellite Aerosol Remote Sensing Over Land, edited by: Kokhanovsky, A. A. and de Leeuw, G., Springer, Berlin, 267293, 2009.

MISR Science Team: MISR Ancillary Data, NASA Atmospheric Science Data Center (ASDC), Hampton, VA, USA https://doi.org/10.5067/TERRA/MISR/MIANCAGP_Ancillary. 001, 2015a.

MISR Science Team: Terra/MISR Level 1, Ellipsoid, version 3, NASA Atmospheric Science Data Center (ASDC), Hampton, VA, USA, https://doi.org/10.5067/Terra/ MISR/MI1B2E_L1.003, 2015b.

MISR Science Team: Terra/MISR Level 1, Geometric Parameters, version 2, NASA Atmospheric Science Data Center (ASDC), Hampton, VA, USA, https://doi.org/10.5067/Terra/ MISR/MIB2GEOP_L1.002, 2015c.

MISR Science Team: Terra/MISR Level 1, Terrain, version 3, NASA Atmospheric Science Data Center (ASDC), Hampton, VA, USA, https://doi.org/10.5067/Terra/MISR/ MI1B2T_L1.003, 2015d.

MISR Science Team: Terra/MISR Level 2, Aerosol, version 2, NASA Atmospheric Science Data Center (ASDC), Hampton, VA, USA, https://doi.org/10.5067/Terra/MISR/ MIL2ASAE_L2.002, 2015e.

Mobley, C. D.: Estimation of the remote-sensing reflectance from above-surface measurements, Appl. Optics, 38, 7442-7455, 1999.

Mobley, C. D., Werdell, J., Franz, B., Ahmad, Z., and Bailey, S.: Atmospheric Correction for Satellite Ocean Color Radiometry, NASA Tech. Memo. 2016-217551, NASA Goddard Space Flight Center, Greenbelt MD, 85 pp., 2016.

Morel, A. and Gentili, B.: A simple band ratio technique to quantify the colored dissolved and detrital organic material from ocean color remotely sensed data, Remote Sens. Environ., 113, 9981011, https://doi.org/10.1016/j.rse.2009.01.008, 2009.

Morel, A. and Prieur, L.: Analysis of variations in ocean color, J. Limnol. Oceanogr., 22, 709-722, 1977.

Morel, A., Antoine, D., and Gentili, B.: Bidirectional reflectance of oceanic waters: Accounting for Raman emission and varying particle phase function, Appl. Optics, 41, 6289-6306, 2002. 
OB.DAAC (Ocean Biology Distributed Active Archive Center): Moderate Resolution Imaging Spectroradiometer (MODIS) Terra Ocean Color Data, NASA OB.DAAC, NASA Goddard Space Flight Center, Greenbelt, MD, USA, NASA Ocean Biology Distributed Active Archive Center (OB.DAAC), Goddard Space Flight Center, Greenbelt MD, USA, 2018.

OBPG (Ocean Ecology Laboratory, Ocean Biology Processing Group): MODIS-Terra L2 aot_869, angstrom, Rrs_443, Rrs_555, Rrs_667, Rrs_678 and 12_flags; NASA Goddard Space Flight Center, Ocean Ecology Laboratory, Ocean Biology Processing Group, available at: https://oceancolor.gsfc.nasa.gov/, last access: 23 January 2019.

O'Reilly, J. E., Maritorena, S., Mitchell, B. G., Siegel, D. A., Carder, K. L., Kahru, M., and McClain, C.: Ocean color chlorophyll algorithms for SeaWiFS, J. Geophys. Res., 103, 2493724953, https://doi.org/10.1029/98JC02160, 1998.

Schuster, G. L., Dubovik, O., and Arola, A.: Remote sensing of soot carbon - Part 1: Distinguishing different absorbing aerosol species, Atmos. Chem. Phys., 16, 1565-1585, https://doi.org/10.5194/acp-16-1565-2016, 2016.

Sinyuk, A., Dubovik, O., Holben, B., Eck, T. F., Breon, F.-M., Martonchik, J., Kahn, R. A., Diner, D., Vermote, E. F., Kaufman, Y. J., Roger, J. C., Lapyonok, T., and Slutsker, I.: Simultaneous retrieval of aerosol and surface properties from a combination of AERONET and satellite data, Remote Sens. Environ., 107, 90108, https://doi.org/10.1016/j.rse.2006.07.022, 2007.

Sinyuk, A., Holben, B. N., Smirnov, A., Eck, T. F., Slutsker, I., Schafer, J. S., Giles, D. M., and Sorokin, M.: Assessment of error in aerosol optical depth measured by AERONET due to aerosol forward scattering, Geophys. Res. Lett., 39, L23806, https://doi.org/10.1029/2012GL053894, 2012.
Wagner, F. and Silva, A. M.: Some considerations about Ångström exponent distributions, Atmos. Chem. Phys., 8, 481-489, https://doi.org/10.5194/acp-8-481-2008, 2008.

Wentz, F. J., Scott, J., Hoffman, R., Leidner, M., Atlas, R., and Ardizzone, J.: Remote Sensing Systems Cross-Calibrated MultiPlatform (CCMP) 6-hourly ocean vector wind analysis product on 0.25 deg grid, Version 2.0, [2000-2017], Remote Sensing Systems, Santa Rosa, CA, available at: http://www.remss.com/ measurements/ccmp/ (last access: April 2017), 2015.

Werdell, P. J. and Bailey, S. W.: The SeaWiFS Bio-optical Archive and Storage System (SeaBASS): Current architecture and implementation, NASA Tech. Memo. 2002-211617, edited by: Fargion, G. S. and McClain, C. R., NASA Goddard Space Flight Center, Greenbelt MD, 45 pp., 2002.

Werdell, P. J. and Bailey, S. W.: An improved in situ data set for bio-optical algorithm development and ocean color satellite validation, Remote Sens. Environ., 98, 122-140, 2005.

Werdell, P., Franz, B., Bailey, S., Feldman, G., Boss, E., Brando, V., Dowell, M., Hirata, T., Lavender, S., Lee, Z., Loisel, H., Maritorena, S., Mélin, F., Moore, T., Smyth, T., Antoine, D., Devred, E., d'Andon, O., and Mangin, A.: Generalized ocean color inversion model for retrieving marine inherent optical properties, Appl. Optics, 52, 2019-2037, 2013.

Witek, M. L., Diner, D. J., Garay, M. J., Xu, F., Bull, M. A., and Seidel, F. C.: Improving MISR AOD Retrievals With LowLightLevel Corrections for Veiling Light, IEEE T. Geosci. Remote Sens., 99, 1-18, https://doi.org/10.1109/TGRS.2017.2727342, 2017.

Witek, M. L., Garay, M. J., Diner, D. J., Bull, M. A., and Seidel, F. C.: New approach to the retrieval of AOD and its uncertainty from MISR observations over dark water, Atmos. Meas. Tech. 11, 429-439, https://doi.org/10.5194/amt-11-429-2018, 2018. 